\title{
PREVALENCE OF BULLYING AND PROFILE OF BULLIES AND VICTIMS AMONG TRIBAL SCHOOL- GOING ADOLESCENTS IN GUJARAT, INDIA
}

\author{
A. Phatak ${ }^{1}$, M. Shinde ${ }^{1}$, B. Gandhi ${ }^{2}$, K. Talati ${ }^{3}$.
}

1. Charutar Arogya Mandal, Central Research Services, Karamsad, India.

2. Foundation for Diffusion of Innovations, Department of Tribal Initiatives, Dahod, India.

3. Foundation for Diffusion of Innovations, Department of Interdisciplinary Research, Vadodara, India.

Background and Aims: Bullying is defined as "Intentional, repeated negative (unpleasant and hurtful) behaviour by one or more persons directed against a person who has difficulty defending himself or herself". Bullying can have short and long-term implications on health, ranging from headache, abdominal pain, \& nausea to clinical depression. Despite cultural differences, certain similarities in gender, age, location and type of victimization were observed. There is scarcity of studies related to bullying in India - more so in tribal areas.

Aim: To determine prevalence of bullying and profile of bullies and victims among school-going children of tribal district of Dahod, India. Methods: Questionnaire in vernacular language (Gujarati) was administered with language support to $6-9$ graders of 4 schools $(n=385)$ in Dahod district. The questionnaire comprised of demographic information, Peer Interaction In Primary Schools(PIPS) and Strength And Difficulty Questionnaire(SDQ)scales. Eight questions were used to screen and categorize participants into bully, victim, bully-victim and not-involved. Descriptive statistics were used to portray characteristics of bullies and victims. ANOVA/Chi square test was applied to determine associations between socio-demographic variables and different traits.

\section{Results: 385 surveys distributed and returned - Response $100 \%$} One form misplaced and one spoiled.

Prevalence of bullying-related involvement was $\mathbf{7 2 . 1 \%}$. Prevalence of bullies was $8.9 \%$, victims was $13.1 \%$, bully-victims was $63.2 \% .14 .9 \%$ of subjects were non-involved.

Bullying-related involvement and Victimization more in Boys.

No association was found between different categories and family type, birth order, number of friends.

Bullying occurred mostly during prayer and commuting.

Only $142(37.1 \%)$ shared the issue with parents/teachers

Bully-victim was the most affected group as per SDQ profile.

Conclusion: Prevalence of bullying in rural schools $(72.1 \%)$ is high as compared to previous studies but with varying methodologies and thresholds used for screening the population.

Guidelines need to be developed to standardize future bullyingrelated research in India.

Empowering students and teachers along with culturally appropriate, evidence-informed, intervention strategy at school level need to be devised.

Group wise comparative means and standard deviations on PIPS and SDQ

\begin{tabular}{|l|l|l|l|l|l|l|}
\hline & Bully only & Victim only & Bully \& Victim & Non-involved & Total & p-value \\
\hline PIPS Bully Score & $4.61(3.76)$ & $4.89(3.97)$ & $10.91(5.04)$ & $2.35(3.49)$ & $8.27(5.77)$ & $<0.001$ \\
\hline PIPS Victim Score & $5.71(5.12)$ & $9.41(8.94)$ & $12.96(5.29)$ & $3.82(4.87)$ & $10.43(6.80)$ & $<0.001$ \\
\hline Total Difficulty Score(SDQ) & $21.86(8.93)$ & $18.8(8.18)$ & $20.45(7.73)$ & $24.08(8.16)$ & $20.95(8.07)$ & $<0.008$ \\
\hline
\end{tabular}

Association of Sociodemographic profile with bullying-related categories

\begin{tabular}{|c|c|c|c|c|c|}
\hline \multirow[t]{2}{*}{ Variable } & Bully only & Victim only & Bully \& Victim & Non-involved & \multirow[t]{2}{*}{ p-value } \\
\hline & \multicolumn{4}{|c|}{$\mathrm{n}(\%)$} & \\
\hline \multicolumn{6}{|c|}{ Gender $(n=383)$} \\
\hline Male & $13(6.1)$ & $24(11.3)$ & $154(72.3)$ & $22(10.3)$ & \multirow[t]{2}{*}{$<0.001$} \\
\hline Female & $21(12.4)$ & $26(15.3)$ & $88(51.8)$ & $35(20.6)$ & \\
\hline \multicolumn{6}{|c|}{ Family Type $(n=363)$} \\
\hline Joint & $31(8.9)$ & $49(14)$ & $216(61.7)$ & $54(15.4)$ & \multirow[t]{3}{*}{0.32} \\
\hline Nuclear & $1(10)$ & 0 & $9(90)$ & 0 & \\
\hline Separated & $1(33.3)$ & 0 & $2(66.7)$ & 0 & \\
\hline \multicolumn{6}{|c|}{ Birth Order $(n=372)$} \\
\hline Eldest & $7(7.5)$ & $11(11.8)$ & $60(64.5)$ & $15(16.1)$ & \multirow[t]{3}{*}{0.76} \\
\hline Youngest & 13(7.6) & $26(15.1)$ & $106(61.6)$ & $27(15.7)$ & \\
\hline In Between & $13(12.1)$ & $11(10.3)$ & $68(63.6)$ & $15(14.0)$ & \\
\hline \multicolumn{6}{|c|}{ Friends n(364) } \\
\hline Up to 6 & $24(9.8)$ & $33(12.5)$ & $166(63.1)$ & $40(15.2)$ & \multirow[t]{2}{*}{0.91} \\
\hline More than 6 & $7(6.9)$ & $14(13.9)$ & $64(63.4)$ & $16(15.8)$ & \\
\hline
\end{tabular}

CONTACT : Mr. Ajay G PHATAK, Central Research Services, Charutar Arogya Mandal, Karamsad-Anand-Gujarat. Pin-388325, Email: ajayqp@gmail.com Mobile: +91 9712926443 